\title{
Evaluation of intake charge hydrogen enrichment in a heavy-duty diesel engine
}

\author{
Emad Monemian ${ }^{1}$, Alasdair Cairns ${ }^{1}$, Mark Gilmore $^{2}$, David Newman ${ }^{2}$, \\ Keith $\operatorname{Scott}^{3}$
}

\begin{abstract}
Concerns over $\mathrm{CO}_{2}$ emissions and global warming continue to enforce the transport sector to reduce the fuel consumption of heavy duty diesel goods vehicles as one major contributor of $\mathrm{CO}_{2}$. Such powertrain platforms look set to remain the dominant source of heavy duty vehicle propulsion for decades to come. The currently reported work was concerned with experimental evaluation of the potential to partially displace diesel with hydrogen fuel, which continues to attract attention as a potential longer term alternative fuel solution whether produced on-board or remotely via sustainable methods. The single cylinder engine adopted was of 2.0 litre capacity, with common rail diesel fuel injection and EGR typical of current production technology. The work involved fumigation of $\mathrm{H} 2$ into the engine intake system at engine loads typically visited under real world driving conditions. Highest practical hydrogen substitution ratios increased indicated efficiency by up to $4.6 \%$ at 6bar IMEPn and $2.4 \%$ at $12 \mathrm{bar}$ IMEPn. In 6bar IMEPn, $\mathrm{CO}_{2}, \mathrm{CO}$ and soot all reduced by $58 \%, 83 \%$ and $58 \%$ respectively while the corresponding reduction of these emissions in 12 bar IMEPn, were $27 \%, 45 \%$ and $71 \%$ respectively toward diesel-only baseline. Under such conditions the use of a pre-injection prior to the main diesel injection was essential to control the heat release and pressure rise rates.
\end{abstract}

\section{Key words:}

Hydrogen, fumigation, diesel, heavy duty, $\mathrm{CO}_{2}$

\section{Introduction}

The Paris Agreement ${ }^{1}$ reached in December 2015 set the target of retaining the increase of earth average temperatures below $2^{\circ} \mathrm{C}$ above preindustrial record. As a result, the commitment to challenge climate change has entered a critical phase as a binding and universal agreement on reducing Green House Gases (GHG), especially $\mathrm{CO}_{2}$. Within the EU, controlling exhaust emissions in the transport sector as the main contributor to $\mathrm{CO}_{2}$ emissions ( 20\%) has forced manufacturers to additionally focus upon Heavy Duty (HD) vehicles, which account for a quarter of $\mathrm{CO}_{2}$ emissions in this sector. $^{2}$

\footnotetext{
${ }^{1}$ University of Nottingham, UK

${ }^{2}$ VN Automotive Ltd, UK

${ }^{3}$ Newcastle University, UK

Corresponding author:

Emad Monemian, University of Nottingham, NG7 2RD

Email: emad.monemian@nottingham.ac.uk
} 
Despite attaining relative high thermal efficiency, HD diesel engines have the major drawback of high engine-out soot and NOx emissions. The Diesel Particulate Filter (DPF) has been developed to inhibit tailpipe soot emissions. However, in addition to high price, the DPF requires periodic enrichment of the fuel-air mixture to increase exhaust temperatures with the aim of removing accumulated soot from the filter (regeneration). This results in an additional fuel consumption penalty. Moreover, in contrast to passenger car vehicles, heavy-duty engines benefit less from measures such as electrification and hybridisation. ${ }^{3}$ In this regard, alternative low carbon fuels become particularly attractive due to high load and journey energy requirement of HD vehicles.

Many researchers have investigated methods for reduction of soot from such diesel engines. One efficient method can be classified as premixed Low Temperature Combustion (LTC). Utilising long ignition delay in these combustion modes permits sufficient mixing before combustion commencement resulting in reduced rich regions within combustion chamber and inhibiting soot formation. $^{4}$ Nevertheless, lower combustion temperatures cause higher $\mathrm{CO}$ and $\mathrm{HC}$ emissions due to less complete combustion. This problem can be solved by substituting part of the diesel fuel with hydrogen. Non-existence of carbon content is a key benefit of burning hydrogen in IC engines, conducting to absence of $\mathrm{CO}, \mathrm{CO}_{2}, \mathrm{uHC}$ and $\mathrm{PM}$ exhaust emissions. This claim neglects any carbon entering the combustion chamber via the lubricant, but significant benefits remain. A critical hurdle is hydrogen supply and storage.

Approximately $95 \%$ of hydrogen is supplied from methane through a process known as 'steam reformation' which yields no overall benefit in $\mathrm{CO}_{2}$ per equivalent mass of diesel. Another method involves electrolysis by renewable energy, which is a zero carbon route but is very costly. Alternatively, a novel possibility for hydrogen acquirement is via on-board steam reformation of part of the liquid hydrocarbon fuel, which improves overall system efficiency by about $5 \%$ via waste exhaust heat recovery.
Storage is among the main areas for development of hydrogen power due to relevant safety issues and physical properties of hydrogen. Although distinct crystalline materials have been suggested for hydrogen storage, hydrides are used for storing significant quantities of hydrogen gas. In 2008, a hydrogen tank using an alloy found by Robin Gremaud could have $60 \%$ less weight than a battery pack. $^{6}$ Besides, cryogenic tanks are other preferences which attempt to improve compatibility, expense and volumetric capacity. As an example of efforts in this area, BMW previously adopted cryogenic tanks for a 7 series mini-fleet to demonstrate improved driving range. The distribution of hydrogen for vehicles at filling stations needs remarkable infrastructure and huge investment. As of 2017, there are 35 public hydrogen stations in the US, with 32 of those located in California. ${ }^{7}$

Several automotive manufacturers including BMW, Ford and Mazda have attempted to utilise hydrogen as an alternative fuel for the IC engine. The BMW Hydrogen 7, powered by a hydrogen ICE, was developed by BMW between 2005 and 2007. This demonstrator adopted the same 6L V12 engine as the gasoline production model but with modifications to allow for dual fuel operation. Overall, the combustion system matched the efficiency values of a baseline turbo-diesel engine at a maximum of $42 \% .^{8}$

Elsewhere, Ford also developed the first vehicle in North America exclusively powered by a hydrogen fuelled IC engine (H2ICE). A Zetec based 2 litre H2ICE with a PFI system was integrated into a P2000 passenger sedan. $\mathrm{CO}_{2}$ emissions were reduced to $0.4 \%$ that of the gasoline case, with metro cycle fuel economy improved by $18 \% .^{9}$ In later work, to achieve the stringent 2010 Phase II Heavy Duty emission standards, Ford re-designed a V10 Triton engine with aim of running a E-450 bus with hydrogen. Following this, the Ford Focus FCV was developed as an alternative hydrogen fuel cell vehicle. ${ }^{10}$ Such FCV vehicles are widely considered to offer considerable promise but only provided the current high costs of fuel cell technology can be 
reduced in the longer term. Hence, in the medium term (at least), the IC engine remains dominant.

There have been numerous other attempts to adopt hydrogen in IC engines. Revolve UK modified the engine of a Ford Transit 2.2L Puma Diesel to operate with PFI injection of hydrogen as the main fuel. As the ignition source, diesel pilot injection was used to allow a permanent dual-fuel mode. ${ }^{11}$ More recently, Alset developed a hybrid hydrogengasoline system that allowed the vehicle to use both fuels individually or at the same time. This technology was implemented on the Aston Martin Rapide S, which was the first vehicle completing the 24 hour Nürburgring race with hydrogen technology. ${ }^{12}$

The unique physical properties of hydrogen make it quite different from conventional fuels, as indicated in Table 1. Due to the very low density, hydrogen's volumetric energy density is small relative to that of diesel even in a compressed storage tank or in liquid state. Hence, a large volume is needed for storing sufficient hydrogen to perform a requisite driving range. ${ }^{13}$ This fact highlights the benefits of hydrogen production through on-board reformation.

Table 1. Physical properties of hydrogen vs. diesel ${ }^{14}$

\begin{tabular}{l|ll}
\hline Parameter & Hydrogen & Diesel \\
\hline Density at $0{ }^{\circ} \mathrm{C}\left[\mathrm{kg} / \mathrm{m}^{3}\right]$ & 0.089 & 830 \\
Stoichiometric air/fuel ratio & 34.3 & 14.5 \\
LHV $[\mathrm{MJ} / \mathrm{kg}]$ & 120 & 42.5 \\
Mixture Calorific value at $\varphi=1\left[\mathrm{MJ} / \mathrm{m}^{3}\right]$ & 3.2 & 3.83 \\
Boiling Temperature $\left[{ }^{\circ} \mathrm{C}\right]$ & -253 & $180-360$ \\
Ignition Limits $[\mathrm{Vol} \%, \varphi]$ & $4-75 \%$, & $0.6-5.5 \%$, \\
Min Ignition Energy at air $(\varphi=1)[\mathrm{mJ}]$ & $0.1-5.0$ & $0.77-2.0$ \\
Autoignition Temperature $\left[{ }^{\circ} \mathrm{C}\right]$ & 585 & 0.24 \\
Laminar Flame Speed at $\varphi=1[\mathrm{~m} / \mathrm{s}]$ & 2.0 & $\sim 250$ \\
Carbon Content $($ Mass \%) & 0 & $0.4-0.8$ \\
\hline
\end{tabular}

According to Table 1, vast ignition limits (4-75\% volumetric concentration in air), enables combustion over a wide domain of fuel-air mixtures including high efficiency lean operation. Furthermore, hydrogen has a relatively high flame speed that leads to higher efficiency. ${ }^{16}$ Hydrogen's high diffusivity facilitates forming a uniform fuelair mixture readily. This is also advantageous in the case of a hydrogen gas leakage, with rapid dispersion. ${ }^{13}$ Low ignition energy of hydrogen and high burning speed makes the mixture of diesel/hydrogen easier to ignite, hence, mitigating misfire and improving performance and emissions. Besides, by increasing the $\mathrm{H} / \mathrm{C}$ ratio, hydrogen enhances the mixture's energy density at lean mixtures. However full load must be supplemented by some means of volumetric efficiency compensation, such as compound boosting. ${ }^{13}$

Comparing with diesel, hydrogen has meaningfully higher specific energy by mass (LHV) enabling a significant proportion of required diesel fuel be substituted by hydrogen in more cost effective way. However, diverse challenges remain including high in-cylinder pressure rise rates and the occurrence of pre-ignition and flashback within the intake system, particularly under heavy loads. The high flame speed of hydrogen is favourable in terms of knock. ${ }^{13}$ However, in-cylinder hotspots exposed during the intake stroke can serve as ignition sources for causing pre-ignition and flashback due to hydrogen's very low ignition energy. In addition, lubricant deposits or the spark-plug electrodes are also thought to initiate flashback. ${ }^{13}$

The injection strategy has considerable influence on the hydrogen mixture's homogeneity and stratification at ignition. Hydrogen direct injection (DI) could have further benefits rather than port fuel injection (PFI) due to providing more volumetric efficiency and avoiding irregular combustion like backfire. ${ }^{17}$ Comparing DI and PFI injection modes, researchers at Graz Technical University concluded that power output with $\mathrm{H} 2 \mathrm{DI}$ was $\sim 17 \%$ higher than that attained via port injection. ${ }^{15}$

The currently reported work has been concerned with the effects of dual fuel on a HD diesel engine, with supplementary hydrogen introduced into the intake in a "fumigation" approach. This approach fits well with two pathways for the reduction of $\mathrm{CO}_{2}$ emissions; hydrogen electrolysed from renewable sources and on-board reformation. 


\section{Methodology}

\subsection{Experimental setup}

The test engine was a boosted HD diesel single cylinder similar to a typical large goods vehicle (LGV) engine. The specifications of the unit are described in Table 2 and Figure 1.

Table 2. Test Engine Specifications

\begin{tabular}{|c|c|}
\hline Parameter & Value \\
\hline Displacement volume & 2.026 lit \\
\hline Bore $\times$ Stroke & $129 \mathrm{~mm} \times 155 \mathrm{~mm}$ \\
\hline Connecting rod length & $256 \mathrm{~mm}$ \\
\hline Geometrical Compression ratio & $16.8: 1$ \\
\hline Type of piston & Re-entrant bowl \\
\hline Number of valves & 4 \\
\hline Intake valve opening / closure & $367 \mathrm{CAD} /-146 \mathrm{CAD}$ \\
\hline Exhaust valve opening / closure & $142 \mathrm{CAD} / 367 \mathrm{CAD}$ \\
\hline Intake and exhaust valve lift & $14 \mathrm{~mm}$ \\
\hline Diesel injection system & $\begin{array}{l}\text { Bosch common rail, } 220 \mathrm{MPa} \max \\
\text { injection pressure, } 8 \text { holes, } 150^{\circ} \\
\text { spray angle }\end{array}$ \\
\hline Diesel fuel & $\begin{array}{l}\text { Diesel - off-road "red" diesel } \\
(\mathrm{LHV}=42.9 \mathrm{MJ} / \mathrm{kg})\end{array}$ \\
\hline Hydrogen System & $\begin{array}{l}\text { Continuous fumigation into intake } \\
\text { port by OMEGA }{ }^{\circledR} \text { flow controller }\end{array}$ \\
\hline Hydrogen fuel & $\begin{array}{l}\mathrm{BOC}^{\circledR} \mathrm{CP} \text { grade hydrogen } \mathrm{N} 5.0 \\
99.999 \% \text { min purity }(\mathrm{LHV}=120 \\
\mathrm{MJ} / \mathrm{kg})\end{array}$ \\
\hline
\end{tabular}

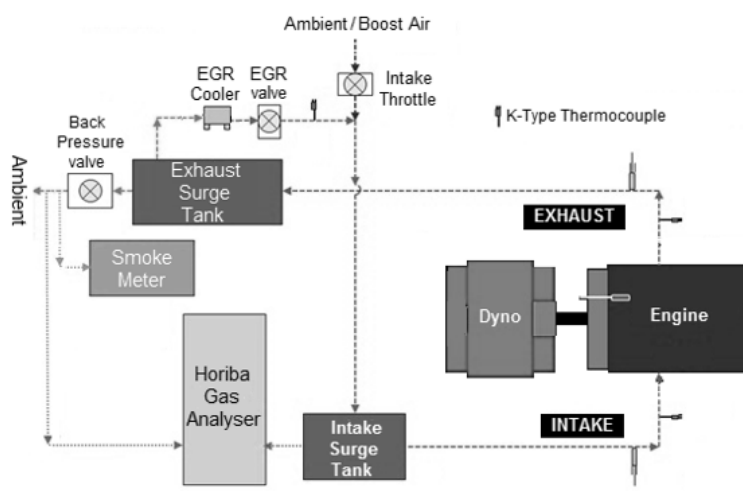

Figure 1. Schematic of HD test engine

Externally boosted intake air flow was controlled by a throttle. High pressure cooled EGR with an electric exhaust back pressure valve allowed mixing of boosted intake air and cooled EGR at the intake surge tank. The diesel injection system comprising
Bosch common rail with a central direct injector was controlled by a separated ECU.

The hydrogen was taken from a gas cylinder and regulated to 7 bar pressure, before being fumigated into the intake pipe downstream of the plenum via an OMEGA ${ }^{\circledR}$ mass flow controller. A schematic of the hydrogen fumigation setup is shown in Figure 2. In order to protect the operator and test facility against hydrogen leakage, an industry standard gas detector and emergency shutdown were installed at the test bay, which could rapidly shut off the hydrogen supply via a solenoid actuated pneumatic valve.

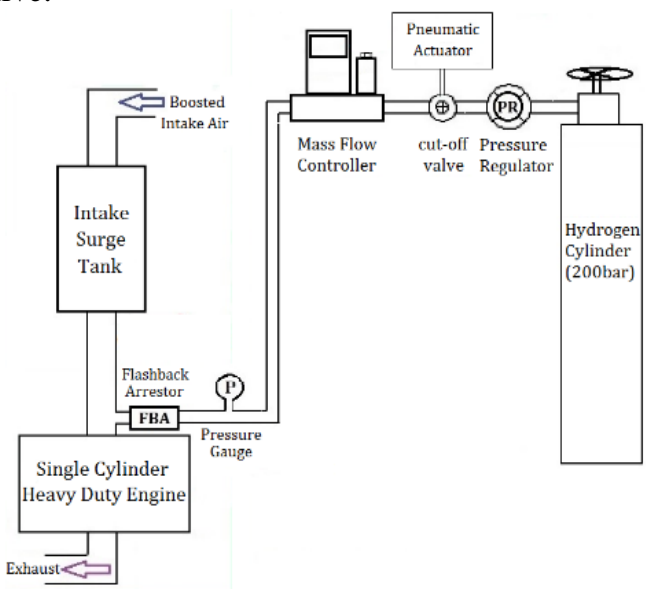

Figure 2. Schematic of Hydrogen Fumigation

The boosted inlet air mixed with the cooled EGR at the intake surge tank. To avoid any risk of ignition at the intake manifold, hydrogen was added after the intake surge tank (into a mix of boosted air and cooled EGR) and at the nearest point to the combustion chamber. A flashback arrestor was also fitted to the hydrogen supply. Only steady-state conditions were considered in this study.

It is worthwhile to mention that the most critical parameter affecting the accuracy of measured data is fuel (diesel) flow rate. The coefficient of variation for fuel flow rate (COV_FFR) over averaged cycles was increasing by more hydrogen enrichment as the highest COV_FFR was $3.10 \%$ and $0.85 \%$ at 6 bar and 12 bar IMEP respectively. Therefore, the diesel flowrate was reasonably stable and hence the measured data had acceptable accuracy. 


\subsection{Measurements}

The $\mathrm{AFR}_{\text {stoich }}$ was specified based on ${ }^{18}$ and global equivalence ratio $(\varphi)$ was calculated using an algorithm explained in ${ }^{19}$. The hydrogen fraction ratio $(\mathrm{HF})$ was calculated basing on energy input, Eq. (1):

$$
H F=\frac{\dot{m}_{\text {hydrogen }} L H V_{\text {hydrogen }}}{\dot{m}_{\text {hydrogen }} L H V_{\text {hydrogen }}+\dot{m}_{\text {diesel }} L H V_{\text {diesel }}}
$$

Two NI DAQ cards were responsible of measured data acquisition. One was receiving encoder signals (with $0.25 \mathrm{CAD}$ resolution) and the other one was used for slower data measurements. Meanwhile an in-house data acquisition program was used for real-time monitoring and recording the operational parameters. Kistler piezoelectric sensor along with an amplifier was used for in-cylinder pressure measurement. In addition, two piezo-resistive sensors measured intake and exhaust pressures in addition to K-type thermocouples for temperature measurement.

CA50, the CAD of $50 \%$ mass fraction burned (MFB) was assumed as the combustion timing. Cyclic variation was presented by COV_IMEPn (coefficient of variation for IMEPn) which was averaged over 500 sampled cycles.

Horiba gas analyser were used for exhaust gaseous emissions ( $\mathrm{NOx}, \mathrm{HC}, \mathrm{CO}$ and $\mathrm{CO}_{2}$ ) sampling after the backpressure valve. EGR rate was calculated as the ratio of $\mathrm{CO}_{2}$ concentration in the intake and exhaust. Soot emission was measured with an AVL 415SE smoke meter. The specific exhaust gas emissions and combustion efficiency $\left(\eta_{c}\right)$ were calculated using the calculations defined in ${ }^{20}$, with wet basis correction of $\mathrm{CO}$ and NOx emissions. The COV_IMEPn and average pressure rise rate (PRR) were limited to $5 \%$ and $20 \mathrm{bar} / \mathrm{CAD}$, respectively.

\subsection{Test conditions}

As indicated in Table 3, two specific operating points were chosen for this work, both with $1200 \mathrm{rpm}$ engine speed. The first operating point is corresponding to $25 \%$ load in a typical HD truck (6bar IMEPn) representing operating point \#7 of the
European Stationary Cycle (ESC13). The second operating point was equivalent to $50 \%$ load (12bar IMEPn) close to point \#5 of the ESC13. ${ }^{21}$

Table 3. Engine Operating Conditions

\begin{tabular}{l|ll}
\hline Parameter & Operating Point 1 & Operating Point 2 \\
\hline Engine Speed & $1200 \mathrm{rpm}$ & $1200 \mathrm{rpm}$ \\
Load (IMEPn) & $6 \mathrm{bar}$ & $12 \mathrm{bar}$ \\
Intake Air Temperature & $309 \mathrm{~K}$ & $318 \mathrm{~K}$ \\
Intake Pressure & $125 \mathrm{kPa}$ & $190 \mathrm{kPa}$ \\
Exhaust Pressure & $135 \mathrm{kPa}$ & $200 \mathrm{kPa}$ \\
EGR Rate & $25 \%$ & $25 \%$ \\
EGR Temperature & $339 \mathrm{~K}$ & $367 \mathrm{~K}$ \\
Rail Pressure & $1250 \mathrm{bar}$ & $1400 \mathrm{bar}$ \\
Diesel Injection Strategy & Pre-injection & Pre-injection \\
H2 Energy Fraction Range & $0 \%$ to $65 \%$ & $0 \%$ to $35 \%$ \\
\hline
\end{tabular}

Figure 3 denotes where the operating points (patterned circles) are placed over the operational map of a HD engine fitted to a truck. The selected test points are placed in a frequent residence area of a generic HD engine driving cycle. The corresponding baseline calibration is based on operating conditions optimised during the previous work in ${ }^{22}$.

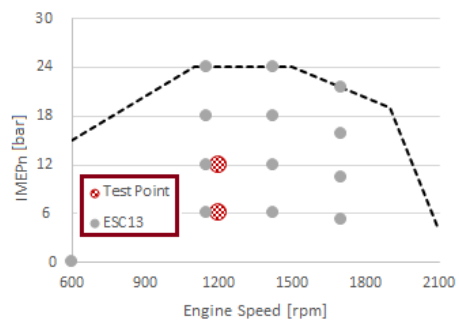

Figure 3. The selected test points with ESC13 points over the HD engine operational map.

\section{Results}

The objective was to achieve the best indicated efficiency-ISsoot trade-off with typical injection pressures and constant optimum injection timings (SOI). It is worth to note that in each operating point, the highest hydrogen fraction was limited by the maximum flow rate of mass flow controller (100 lit/min). In the following section the results of the maximum hydrogen energy fractions obtained (HF $=65 \%$ at $\mathrm{A} 25$ and $\mathrm{HF}=30 \%$ at $\mathrm{A} 50$ ) are thoroughly reported in terms of combustion characteristics and exhaust emissions. 


\subsection{Combustion Analysis}

Initially, a diesel-only test was performed with both single and pre-injection. As seen in Figure 4(a), preinjection enabled reducing the heat release rate with lower pressure rise rate (PRR). The same phenomenon was observed during hydrogen fumigation while keeping the SOIs fixed (with lower main injection duration), as indicated in Figure 4(b). Pre-injection resulted in advancing SOC and reducing ignition delay.
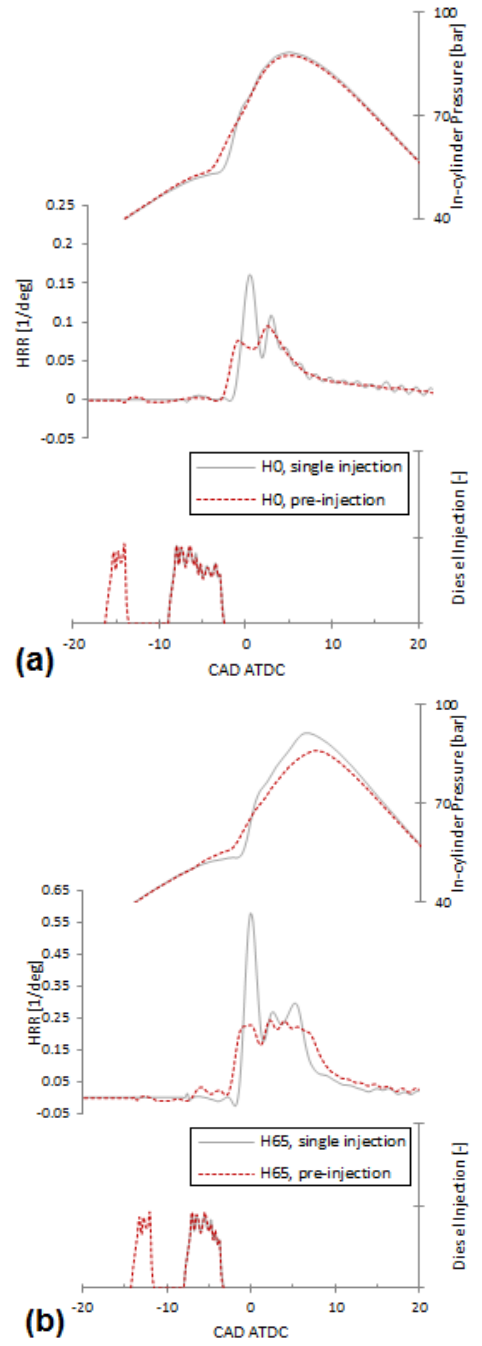

Figure 4. Use of pre-injection to reduce engine noise_A25 (a) diesel-only (0\% H2) (b) dual-fuel $(65 \%$ $\mathrm{H} 2)$
Comparing H65 with $\mathrm{H} 0$ in A25 single injection mode, the H65 has a significant higher HRR with shorter combustion duration. This shows one effect of hydrogen in accelerating the combustion process. As single injection resulted in very high in-cylinder pressure rise (> 20 bar/CAD) with remarkable higher HHR, the pre-injection strategy was chosen for all test cases with aim of reducing combustion noise.

The in-cylinder pressure and heat release profiles of two different HFs are shown in Figure 5. While hydrogen addition shows no significant effect on pressure profile, the $\mathrm{H} 65$ heat release is more than H40 due to higher hydrogen concentration. In addition to shorter combustion duration, H65 has higher indicated efficiency ( 6\%) c.f. H40.

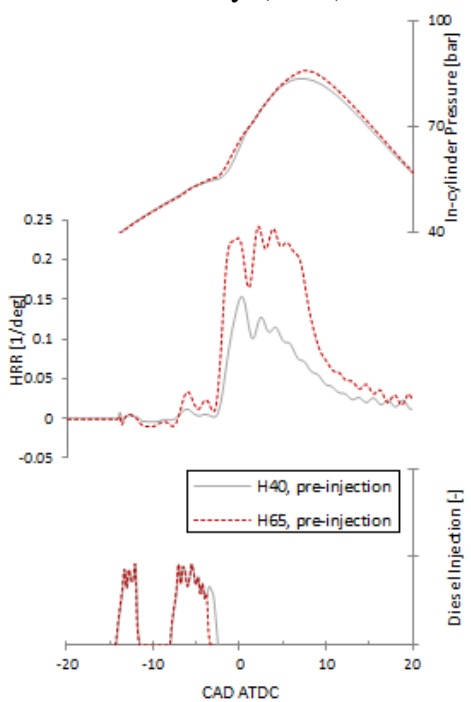

Figure 5. Effect of H2 energy fraction using preinjection_A25

Comparing $\mathrm{H} 30$ and $\mathrm{H} 15$ in A50 mode, hydrogen fraction increase resulted in higher peak in-cylinder pressure. Indeed, a separation emerges from the second stage of heat release for $\mathrm{H} 30$, as seen in Figure 6. A trend similar to A25, i.e. shorter combustion duration and higher indicated efficiency (in smaller scale) was seen in A50 as H30 has $3 \%$ higher indicated efficiency than H15. The reason for this is that due to faster combustion, less heat was transferred to cylinder wall. 


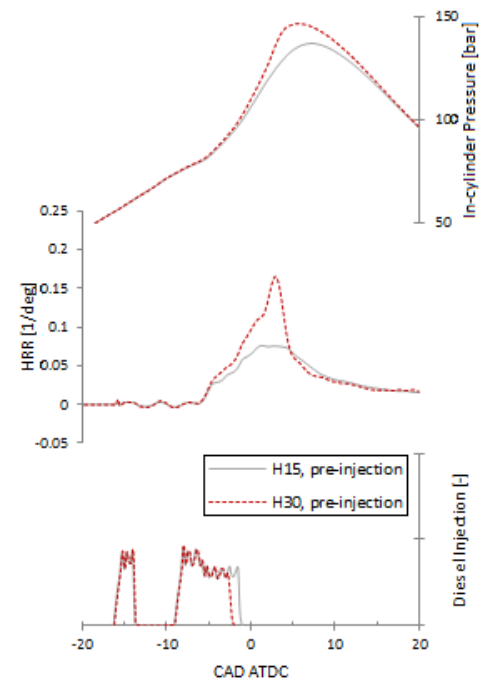

Figure 6. Effect of $\mathrm{H} 2$ energy fraction using preinjection_A50

\subsection{Combustion Characteristics}

In this section, the effects of hydrogen fumigation in two test operating points over combustion and incylinder flow properties are laid out in Figure 7. Air-fuel ratio was fairly constant for both loads with leaner mixture at A25. A steep reduction in volumetric efficiency at both test points was observed by increasing $\mathrm{H} 2$ fraction due to displacement of intake air with hydrogen of low molecular weight but higher LHV. Cycle-to-cycle variability is fairly constant against the hydrogen fraction, although A25 illustrates higher COV but both loads show reasonable COV_IMEPn $(<5 \%)$.

The CA10-CA50 represents the premixed combustion part which initiates and dominates the whole combustion process. This parameter was pretty freezing in A25 but it was decreasing monotonically by rising $\mathrm{H} 2$ fraction. These trends at two loads are similar to combustion timing (CA50). Besides, combustion duration (CA10CA90) for both loads shows descending with shorter duration for A25. A similar trend is reported in ${ }^{23}$. This reflects the provoking property of hydrogen combustion which is bold in the low load.

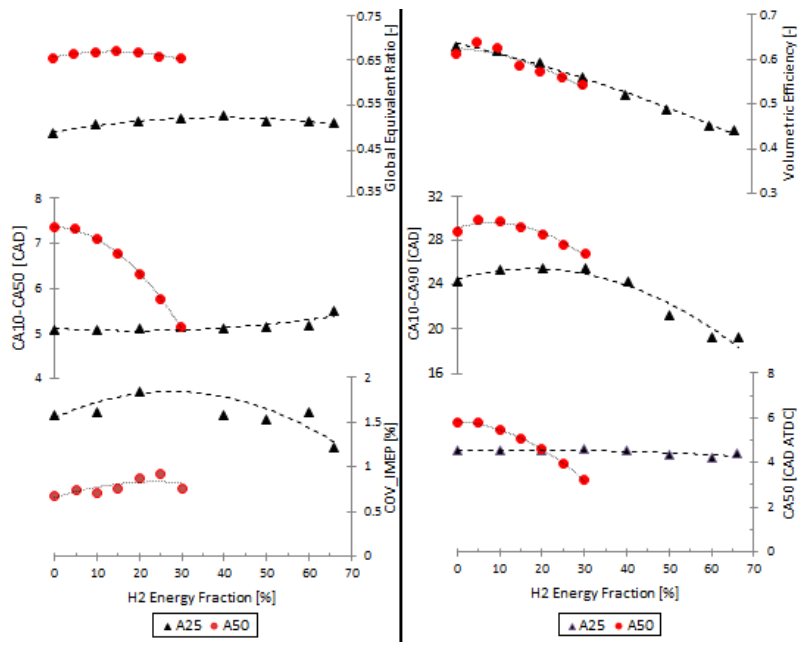

Figure 7. Combustion characteristics (A25 and A50)

\subsection{Exhaust emissions and performance}

The addition of $\mathrm{H} 2$ had an overall positive influence on $\mathrm{CO}_{2}$ and most pollutant emissions, as illustrated in Figure 8. ISSoot, ISCO and $\mathrm{ISCO}_{2}$ all decrease steeply with increasing hydrogen fraction for both loads due to $\mathrm{H} / \mathrm{C}$ ratio reduction. As might be expected, ISNOx increases with higher mass flow of hydrogen, which accelerates combustion and leads to higher temperatures. The trends shown in Figure 8 are can be justified with NOx-equivalence ratio correlation presented in ${ }^{24}$. As average equivalence ration at A25 was near NOx rising threshold $(\varphi=0.5)$, this resulted in relatively low increase of NOx emission ( $26 \%$ c.f. diesel-only) in 6bar IMEPn. However, the NOx increase was significant at 12 bar IMEPn which exceeded $56 \%$ as the equivalence ratio was higher $(\varphi=0.66)$ at $\mathrm{A} 50$. A same NOx trend was observed by relevant work in ${ }^{5}$.

One interesting characteristic with hydrogen fumigation was remaining the ISHC fairly reluctant. The emission alteration for highest hydrogen 
fractions in two test points regarding the diesel-only baseline is presented in Table 4.

Table 4. Emissions alteration of highest HFs to diesel baseline

\begin{tabular}{c|lllll}
\hline Test Point & ISsoot & ISNOx & ISCO & ISHC & ISCO2 \\
\hline A25 & $-58 \%$ & $+26 \%$ & $-83 \%$ & $+11 \%$ & $-58 \%$ \\
A50 & $-71 \%$ & $+56 \%$ & $-45 \%$ & $-21 \%$ & $-27 \%$ \\
\hline
\end{tabular}

Adding small amounts of hydrogen led to slight reduction in indicated efficiency, potentially associated with reduced ratio of specific heats due to displacement of air. The reason for initial drop in efficiency could be due to 'hydrogen slip' (incomplete combustion of hydrogen) as claimed in 5 . However, at higher substitution ratio the faster combustion of hydrogen outweighed this effect and led to improved efficiency especially after hydrogen's lower flammability limit (LFL $=4 \%$ Vol). At A25, $\eta_{\text {ind }}$ has a detrimental effect in the small hydrogen fractions until $\mathrm{HF}=30 \%$, where after efficiency starts to rise significantly until $\eta_{\text {ind }}$ $=46.5 \%$. For A50, elevated $\eta_{\text {ind }}$ starts to recover at $\mathrm{HF}=10 \%$ and reaches a peak of $46.4 \%$ at the highest attainable $\mathrm{HF}$.

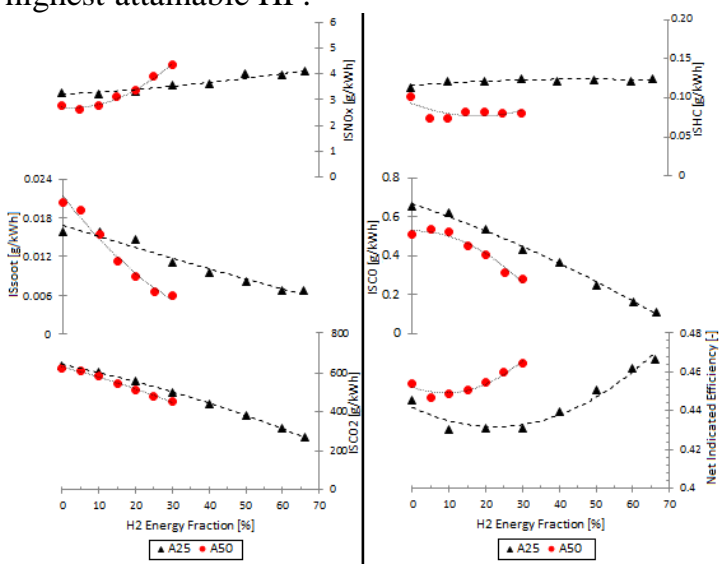

Figure 8. Exhaust Emissions and Performance (A25 and A50)

\section{Conclusion}

The work was concerned with experimental study of the effects of hydrogen fumigation on HD diesel engine combustion, performance, fuel consumption and emissions. The experiments were undertaken at two part load sites of high residency on the drive cycle, with engine speed fixed at $1200 \mathrm{rpm}$ but engine output set to $25 \%$ and $50 \%$ load. At each site a relatively wide sweep of hydrogen addition was performed. The following conclusions were made:

1. Diesel/hydrogen dual-fuel combustion with fixed SOI resulted in relatively low increase of NOx emission $(\sim 26 \%)$ in 6bar IMEPn. However, this increase was significant at $12 \mathrm{bar}$ IMEPn which exceeded $56 \%$.

2. Highest hydrogen substitution ratios increased indicated efficiency by up to $4.6 \%$ at $6 \mathrm{bar}$ IMEPn and $2.4 \%$ at 12 bar IMEPn.

3. Higher hydrogen energy fractions required for optimum SOI led to the need to retard the diesel injection timing. The use of a pre-injection prior to the main diesel injection was essential to control heat release and pressure rise rates.

4. $\mathrm{CO} 2, \mathrm{CO}$ and soot all reduced by $58 \%, 83 \%$ and $58 \%$ respectively in 6bar IMEPn.

5. In 12 bar IMEPn, reduction of $\mathrm{CO} 2, \mathrm{CO}$ and soot were $27 \%, 45 \%$ and $71 \%$ respectively toward diesel-only baseline.

6. According to Euro VI emission regulation, both $\mathrm{CO}$ and $\mathrm{HC}$ could fully meet the limits. Smoke met limits partially i.e. at higher $\mathrm{H} 2$ energy fraction and NOx could meet the $0.4 \mathrm{~g} / \mathrm{kWh}$ limit of Euro VI with NOx after-treatment of $90 \%$ conversion efficiency.

\section{Funding}

This work was supported by VN Automotive Ltd. The support of the EPSRC (Grant EP/N50841X/1) is also gratefully acknowledged.

\section{Acknowledgement}

The authors would like to thank the technicians Andrew Selway and Eamon Wyse for their assistance in commissioning the test rig.

\section{Declaration of conflict of interest}

The authors declare that there is no conflict of interest. 


\section{References}

1. Adoption of the Paris Agreement, United Nations, Framework Convention on Climate Change, FCCC/CP/2015/L.9/Rev.1, 12 Dec 2015

2. "Road transport: Reducing CO2 emissions from vehicles", European Commission, Retrieved 2016-07-22.

3. Reitz RD. Directions in internal combustion engine research. Combust Flame 2013; 160:1-8. http://dx.doi.org/10.1016/j.combustflame.2012.11.002

4. Rolf D. Reitz, Ganesh Duraisamy "Review of high efficiency and clean reactivity controlled compression ignition (RCCI) combustion in internal combustion engines", Progress in Energy and Combustion Science 46 (2015) 12-71, 2015

5. Morgan, R., Atkins, P., Atkins, A., Lenartowicz, C. et al. "Effect of Hydrogen Fumigation in a Dual Fueled Heavy Duty Engine", SAE Technical Paper 2015-24-2457, 2015, doi:10.4271/2015-24-2457.

6. 'Light Weight Hydrogen 'Tank' Could Fuel Hydrogen Economy", sciencedaily.com, 2008-11-05.

7. Alternative Fueling Station Counts by State, Alternative Fuels Data Centre, accessed in 2017-06-12

8. https://en.wikipedia.org/wiki/BMW_Hydrogen_7

9. S. Szwabowski, S. Hashemi, W. Stockhausen, R. Natkin, L. Reams, D. Kabat and C. Potts "Ford Hydrogen Engine Powered P2000 Vehicle", SAE paper 2002-01-0243, 2002.

10. R. J. Natkin, A. R. Denlinger, M. A. Younkins, A. Z Weimer, S. Hashemi and A. T. Vaught "Ford $6.8 \mathrm{~L}$ Hydrogen IC Engine for the E-450 Shuttle Van", SAE paper 2007-01-4096, 2007.

11. "Bi-fuel hydrogen-diesel conversion", Revolve UK, retrieved 2016-09-15 http://www.revolve.co.uk/projects/bifueldieselconversion

12. Alset Global "Our Solutions", retrieved 2016.09.18 http://alset.at/our-solutions/

13. "Hydrogen Fuel Cell Engines and Related Technologies", College of the Desert, Dec 2001

14. Periodic Table of Elements - Hydrogen: http://environmentalchemistry.com/yogi/periodic/H.html

15. Andreas Wimmer, Thomas Wallner, Jürgen Ringler and Falk Gerbig "H2-Direct Injection - A Highly Promising Combustion Concept", SAE paper 2005-01-0108, 2005.

16. NASA Technical Note, May 1977, "Emissions and Total Energy Consumption of a Multicylinder Piston Engine Running on Gasoline and a Hydrogen-Gasoline Mixture"

17. Arash Hamzehloo, Pavlos Aleiferis "Numerical Modelling of Mixture Formation and Combustion in DISI Hydrogen Engines with Various Injection Strategies", SAE paper 2014-01-2577, 2014.

18. Heywood JB "Internal combustion engine fundamentals" 1st edition, McGraw-Hill, 1988

19. Silvis WM, "An algorithm for calculating the air/fuel ratio from exhaust emissions", SAE Paper 970514, 1979. http://dx.doi.org/10.4271/970514

20. Economic Commission for Europe of the United Nations (UN/ECE). Regulation No 49 - uniform provisions concerning the measures to be taken against the emission of gaseous and particulate pollutants from compression- ignition engines and positive ignition engines for use in vehicles. Off J Eur Union 2013.

21. DieselNet, "Emissions Standards: Europe: Heavy-Duty Truck and Bus Engines", accessed Sep 2016 https://www.dieselnet.com/standards/eu/hd.php,

22. Vinícius B. Pedrozo et al., "Experimental analysis of ethanol dual-fuel combustion in a heavy-duty diesel engine: An optimisation at low load", Applied Energy 165 (2016) 166182, 2016 http://dx.doi.org/10.1016/j.apenergy.2015.12.052

23. A.E. Dhole, R.B. Yarasu, D.B. Lata "'Investigations on the combustion duration and ignition delay period of a dual fuel diesel engine with hydrogen and producer gas as secondary fuels", Applied Thermal Engineering 107 (2016) 524-532, 2016 http://dx.doi.org/10.1016/j.applthermaleng.2016.06.151

24. S. Verhelsta and T. Wallnerb, "Hydrogen-Fueled Internal Combustion Engines", Progress in Energy and Combustion Science, 2009 http://hdl.handle.net/1854/LU-818298

\section{Nomenclature}

\begin{tabular}{l|l}
\hline AFR $_{\text {stoich }}$ & Stoichiometric Air-Fuel Ratio \\
CAD & Crank Angle Degree \\
COV & Coefficient of Variation \\
DAQ & Data Acquisition \\
DI & Direct Injection \\
DPF & Diesel Particulate Filter \\
ECU & Engine Control Unit \\
EGR & Exhaust Gas Recirculation \\
ESC & European Stationary Cycle \\
FCV & Fuel Cell Vehicle \\
GHG & Green House Gases \\
HD & Heavy Duty \\
HF & Hydrogen Fraction \\
HRR & Heat Release Net \\
ICE & Internal Combustion Engine \\
IMEPn & net Indicated Mean Effective Pressure \\
ISsoot & Indicated Specific soot \\
LFL & Lower Flammability Limit \\
LGV & Large Goods Vehicle \\
LHV & Lower Heating Value \\
LTC & Low Temperature Combustion \\
MFB & Mass Fraction Burned \\
PFI & Port Fuel Injection \\
PM & Particulate Matter \\
PRR & Pressure Rise Rate \\
SOI & Start of Injection \\
uHC & Unburned Hydrocarbon \\
$\varphi$ & Equivalence Ratio \\
$\eta_{\mathrm{c}}$ & Combustion efficiency \\
$\eta_{\text {ind }}$ & Indicated Efficiency \\
&
\end{tabular}

